\title{
Efficacy of inhaled salmeterol in the management of smokers with chronic obstructive pulmonary disease: a single centre randomised, double blind, placebo controlled, crossover study
}

\author{
Charlotte Suppli Ulrik
}

\begin{abstract}
Background - The acute response to bronchodilators in patients with chronic obstructive pulmonary disease (COPD) is modest; it has, however, been suggested that these patients may benefit from long term treatment.

Methods - To investigate the efficacy of salmeterol in smokers with moderate to severe COPD a double blind, randomised, crossover comparison was performed between salmeterol (50 $\mu \mathrm{g}$ twice daily) and placebo in 63 patients with stable COPD (mean age 65 years). Prior to inclusion, all patients had a forced expiratory volume in one second $\left(F E V_{1}\right)$ of $<60 \%$ of predicted and an improvement in $\mathrm{FEV}_{1}$ of $<15 \%$ following $400 \mu \mathrm{g}$ inhaled salbutamol. Patients received four weeks of therapy with each of the treatment regimens. Assessment of efficacy was made with recording of morning and evening peak expiratory flow rates (PEF), respiratory symptoms, and use of rescue salbutamol. FEV 1 was measured before and after nebulised salbutamol prior to randomisation and at the end of each treatment period.
\end{abstract}

Results - Morning PEF values were higher during the salmeterol than during the placebo period, although the mean treatment difference was small (12 $1 / \mathrm{min}(95 \%$ confidence limits 6 to 17)). No difference in mean evening PEF values was found. Diurnal variation in $P E F$, assessed as the difference between the morning PEF and that of the previous evening, was more pronounced during the placebo than during the salmeterol period. The mean spirometric values (including reversibility in

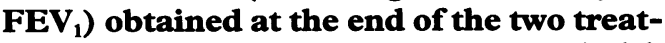
ment periods were similar. Compared with placebo, treatment with salmeterol was associated with lower daytime and night time symptom scores and less use of rescue salbutamol both during the day and the night. The patients rated the treatment with salmeterol better than treatment with placebo.

Conclusions - This study shows that, compared with placebo, treatment with salmeterol produces an improvement in respiratory symptoms and morning PEF values in patients with moderate to severe
COPD. Treatment with long acting $\beta$ agonists may therefore result in an improvement in functional status, even in patients suffering from apparently nonreversible obstructive pulmonary disease. (Thorax 1995;50:750-754)

Keywords: chronic obstructive pulmonary disease, salmeterol, controlled trial.

Beta $_{2}$ adrenoceptor agonists have been the mainstay of treatment for asthma for many years. They induce prompt relief of symptoms, an increase in lung function, and protection against various bronchoconstrictor agents in patients with asthma. Drugs such as salbutamol and terbutaline are also widely used for treatment of non-reversible chronic obstructive pulmonary disease (COPD), although it is well known that the response to such drugs is, at best, modest. It has, however, been suggested that these patients may benefit from long term treatment with bronchodilators, ${ }^{1}$ even when an acute response to such drugs cannot be demonstrated. ${ }^{2}$

Salmeterol is a potent selective $\beta_{2}$ agonist that has been shown to have a duration of action of more than 12 hours in adult asthmatic subjects, ${ }^{3}$ and has been shown to have a protective effect against bronchoconstrictor agents lasting up to 12 hours. ${ }^{4}$ Treatment with salmeterol might therefore be expected to have a beneficial effect in patients with COPD.

This study was designed to investigate the efficacy of salmeterol $(50 \mu \mathrm{g})$ given as dry powder twice daily versus placebo in patients with moderate to severe non-reversible chronic obstructive lung disease.

\section{Methods}

PATIENTS

Patients enrolled in the study were required to be aged over 40 years, to be current smokers, to have cough and phlegm production on most days for at least three months a year for at least two consecutive years, baseline $\mathrm{FEV}_{1}$ of $1 \cdot 0-2 \cdot 01$, and $<60 \%$ of the predicted value, ${ }^{5}$ an $\mathrm{FEV}_{1} / \mathrm{FVC}$ ratio below $60 \%$, and nonreversible airways obstruction in a stable phase, defined as an increase in $\mathrm{FEV}_{1}$ $\left(\left[F V_{1 \text { after }}-\mathrm{FEV}_{\text {1before }}\right] / \mathrm{FEV}_{\text {1before }}\right)$ of $<15 \%$ or $300 \mathrm{ml} 30$ minutes after inhalation of $0.4 \mathrm{mg}$ 
Table 1 Symptom scores

Night time symptom score

$0=$ No symptoms during the night

$1=$ Symptoms causing you to wake once or to wake early

$2=$ Symptoms causing you to wake twice or more (including waking early)

3 =Symptoms causing to you to be awake for most of the night

$3=$ Symptoms causing to you to be awake for most
$4=$ Symptoms so severe that you did not sleep at all

Daytime symptom score

$0=$ No symptoms during the day

$1=$ Symptoms for one short period during the day

$2=$ Symptoms for two or more short periods during the da

$3=$ Symptoms for most of the day which did not affect your normal daily activitie

$4=$ Symptoms for most of the day which did affect your normal daily activities

$5=$ Symptoms so severe that you could not go to work or perform normal daily activities
Peak expiratory flow rate (PEF)

$\mathrm{PEF}$ was measured three times twice daily with a mini-Wright PEF meter before the morning and evening doses of the study drug and the values recorded on diary cards.

Symptom scores and use of rescue $\beta$ agonist Daily diary cards of symptom scores (table 1) were kept throughout the study period. Extra use of the $\beta$ agonist (salbutamol) was also recorded.

\section{Subjective patient evaluation}

At the completion of each treatment period the patients were asked to assess the subjective effect of the treatment on a scale from 1 to 4 . before inclusion), and a total symptom score (daytime and night time) of 1 or more on five of the last seven days of the run-in period or a total symptom score (daytime and night time) of 2 or 3 on at least seven days of the run-in period (table 1). The symptom scoring system has been used in previous studies ${ }^{67}$ where scores were closely correlated to objective parameters such as $\mathrm{FEV}_{1}$ and peak expiratory flow rates (PEF).

Patients with a known history of asthma, allergic rhinitis or atopic dermatitis, clinical instability as judged by hospital admissions for their obstructive lung disease within the month prior to entry, serious clinical or laboratory uncontrolled disease such as hypertension and chronic left ventricular failure, or treatment with inhaled steroids within the previous six months were excluded.

A total of 77 patients entered the run-in period of whom 66 met the final entry criteria and were randomised to receive treatment. Of these 66 patients three did not complete the study. One was unwilling to comply with the study protocol and two withdrew for personal reasons. On entry into the study all patients were taking inhaled $\beta$ agonists and 19 were taking theophylline. Written informed consent was obtained from all patients and the protocol was approved by the ethics committee of Copenhagen and Frederiksberg counties.

\section{PATIENT ASSESSMENTS}

Patients attended the clinic on five occasions during the 12 weeks of the study and all evaluations were performed by one person (CSU). At the first visit demographic details were recorded and blood samples taken for biochemical and haematological analysis.

\section{Spirometry}

Patients were assessed at the same time of day at each visit. Salbutamol was omitted for four hours and study medication (salmeterol or placebo) for at least 24 hours before testing. The $\mathrm{FEV}_{1}$ and forced vital capacity (FVC) were measured with a Vitalograph dry wedge spirometer using the highest of three recordings. The measurements were repeated 15 minutes after inhalation of $5 \mathrm{mg}$ salbutamol solution from a jet nebuliser (Pari Inhalierboy).

\section{STUDY MEDICATION}

The study was of a randomised, double blind, placebo controlled, crossover design. There was a two week run-in period in which patients took a salbutamol Diskhaler $(0.4 \mathrm{mg}$ per dose) when necessary for the relief of symptoms. This same rescue medication was also available during the treatment periods. After the run-in period patients who fulfilled the entry criteria were randomly allocated to receive either salmeterol $(50 \mu \mathrm{g})$ twice daily for four weeks followed by placebo twice daily for four weeks or vice versa. Use of the study medication (salmeterol or placebo) was stopped on the day before the visit to the clinic. Patient compliance was checked by counting the unused medication at the end of each treatment period.

\section{CONCOMITANT MEDICATION}

At the start of the run-in period all oral, rectal, or inhaled $\beta$ agonists (other than the salbutamol inhaler provided) and anticholinergic drugs were withdrawn. The patients on methylxanthines continued to use them at unchanged doses through the study. Short courses of oral corticosteroids were allowed during exacerbations.

\section{DATA ANALYSIS}

To be included in the analysis of a variable patients had to have provided at least four days of data for that variable during the run-in period and data from at least 10 days in the last three weeks of each four week treatment period. In treatment regimens data on the chosen outcome variables were tested for period effect and carryover effect. ${ }^{8}$ There was no washout period but, to minimise the possibility of carryover effect, the first week of each treatment period was excluded from the analysis.

Mean morning and evening PEF from data recorded on the diary cards were chosen as the primary end points before the study and therefore used as a basis for calculating sample size. Data from comparative studies of salmeterol were used to estimate the residual standard deviation of mean daily PEF measureorder to permit an analysis comparing the two 
Table 2 Mean (SD) baseline characteristics of the patients with chronic obstructive pulmonary disease according to treatment group

\begin{tabular}{|c|c|c|}
\hline & $\begin{array}{l}\text { Salmeterol/placebo } \\
(n=31)\end{array}$ & $\begin{array}{l}\text { Placebo/salmeterol } \\
(n=32)\end{array}$ \\
\hline $\begin{array}{l}\text { M/F } \\
\text { Age (years) } \\
\text { Smoking (pack years)* }\end{array}$ & $\begin{array}{l}15 / 16 \\
64 \cdot 3(7 \cdot 6) \\
42 \cdot 2(17 \cdot 6)\end{array}$ & $\begin{array}{l}18 / 14 \\
65 \cdot 5(7 \cdot 9) \\
45 \cdot 2(18 \cdot 7)\end{array}$ \\
\hline $\begin{array}{l}\text { FEV }_{1} \\
\text { Before bronchodilation } \\
\text { In litres } \\
\text { As \% predicted } \\
\text { (range) }\end{array}$ & $\begin{array}{l}1 \cdot 21(0 \cdot 25) \\
46 \cdot 1(9 \cdot 7) \\
(29 \cdot 1-59 \cdot 6)\end{array}$ & $\begin{array}{c}1 \cdot 24(0 \cdot 27) \\
44 \cdot 6(8 \cdot 0) \\
(28 \cdot 3-59 \cdot 2)\end{array}$ \\
\hline $\begin{array}{l}\text { After salbutamol } \\
\text { In litres } \\
\text { As \% predicted } \\
\text { FEV } / \text { FVC (\%) }\end{array}$ & $\begin{array}{ll}1 \cdot 37 & (0 \cdot 27) \\
50 \cdot 5 & (9 \cdot 1) \\
53 \cdot 8 & (5 \cdot 8)\end{array}$ & $\begin{array}{l}1.39(0.31) \\
52 \cdot 5(11 \cdot 5) \\
52.0(6.2)\end{array}$ \\
\hline
\end{tabular}

* All patients enrolled in the study were current smokers.

Table 3 Comparison of mean (SE) pulmonary function, median (range) symptom score and use of rescue salbutamol for salmeterol and placebo periods

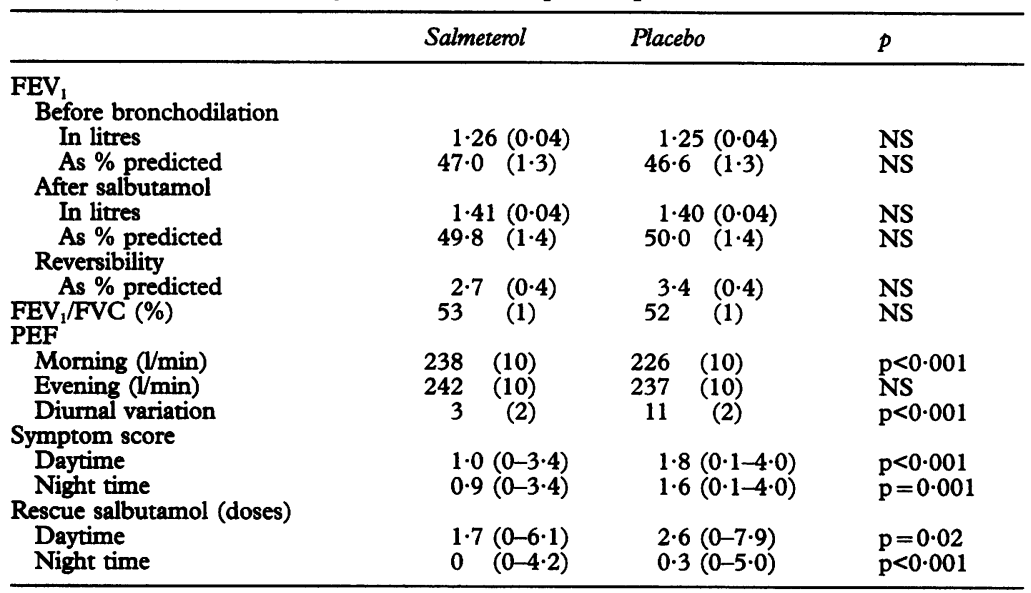

For definitions, see text.
Paired $t$ tests with two tailed probability were used to compare values for $\mathrm{FEV}_{1}, \mathrm{FVC}, \mathrm{FEV}_{1}$ / FVC, and reversibility (for definition see above) obtained at the end of the two treatment periods.

The median difference between the two treatment periods in the percentage of days and nights with a symptom score of 0 and no additional salbutamol were calculated and subjected to Wilcoxon rank sum analysis. For each patient the median daytime and night time symptom score and the median number of additional daytime and night time salbutamol doses were obtained by sequence group, and Prescott's test was used to assess the treatment difference. Wilcoxon rank sum analysis was also used to assess the difference in median subjective patient scoring.

\section{Results}

The mean (SD) age of the 63 patients who completed the study was 65 (8) years and the mean (SD) number of pack years smoked was 44 (18). The baseline $\mathrm{FEV}_{1}$ as a percentage of predicted value ranged from $28 \%$ to $59 \%$; no significant differences were found between the two sequence groups (table 2).

\section{PEF MEASUREMENTS}

Morning PEF values were significantly higher during the salmeterol period than during the placebo period. The mean (SE) morning PEF nificance using a $t$ test.

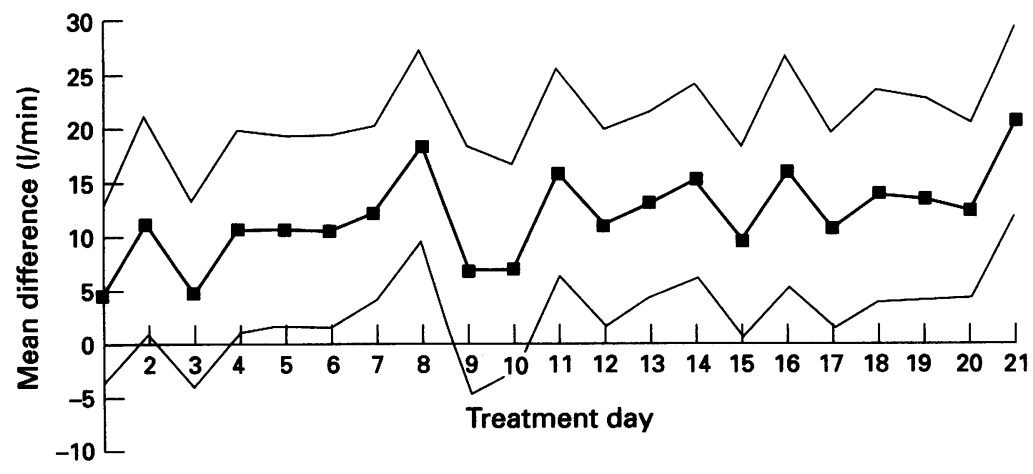

Mean difference (with 95\% confidence limits) in morning peak expiratory flow (PEF) between treatment with salmeterol and placebo in 63 patients with moderate to severe COPD $(p<0 \cdot 001)$. value during the salmeterol period was 238 (10) $1 / \mathrm{min}$ and the corresponding value during the placebo period was 226 (10) $1 / \mathrm{min}$ (table $3)$. The mean treatment difference was $121 /$ min (95\% confidence limits 6 to $17 ; \mathrm{p}<0.001)$ (figure). The mean evening value was 242 (10) $1 /$ min during the salmeterol period and 237 (10) $1 / \mathrm{min}$ during the placebo period $(p>0 \cdot 1)$. Diurnal variation in PEF, assessed as the difference between the morning PEF and that of the previous evening, was significantly more pronounced during the placebo period than during the salmeterol period $(p<0.001)$ although the magnitude of the mean treatment difference was small (7(2) $1 / \mathrm{min}$ ). were calculated for each patient. The treatment mean difference was estimated, together with 95\% confidence limits, and tested for sig-

ment. From these studies estimates of 35-40 V min were found for both morning and evening ceed $401 / \mathrm{min}$. Using an SD of $40 \mathrm{l} / \mathrm{min}$ power of 0.90 to detect a mean difference PEF of $10 \mathrm{l} / \mathrm{min}$ at the $5 \%$ significance level.

For each of the two treatment periods the mean PEF values in the morning and evening and the mean difference between the morning

\section{FEV $_{1}$ AND FVC MEASUREMENTS}

The mean baseline $\mathrm{FEV}_{1}, \mathrm{FVC}$, and $\mathrm{FEV}_{1} /$ FVC values were similar at the end of the two treatment periods and, likewise, no differences in mean reversibility in $\mathrm{FEV}_{1}$ or mean $\mathrm{FEV}_{1}$, FVC, and $\mathrm{FEV}_{1} / \mathrm{FVC}$ values obtained after administration of salbutamol were found between the two treatment periods (table 3 ).

Both the daytime and night time median symptom scores were significantly lower during the salmeterol period than during the placebo period ( $p<0.001$ for both; table 3 ), whereas no difference in median percentage of days or nights with a symptom score of 0 was found between the two treatment periods.

\section{SYMPTOM SCORE}




\section{RESCUE MEDICATION}

The patients were allowed to use salbutamol for acute relief of respiratory symptoms during both treatment periods. Compared with placebo treatment with salmeterol was associated with significantly less use of rescue salbutamol both during the day and the night $(p=0.02$ and $\mathrm{p}<0.001$, respectively; table 3 ). The median percentage of nights when no additional salbutamol was used was significantly higher during the salmeterol period than during the placebo period $(p<0.01)$, whereas the percentage of days when no rescue salbutamol was used did not differ between the two treatment periods.

\section{SUBJECTIVE ASSESSMENT}

After the completion of each treatment period the patients were asked to assess the subjective effect of the treatment. The salmeterol period was rated significantly higher than the placebo period $(p=0.01)$.

\section{SIDE AND ADVERSE EFFECTS}

The reported incidence and nature of both side effects and adverse events during the two treatment periods were similar. Fifty three of the 63 patients did not report any side or adverse effects at all during the whole study period. Tremor, sweating, and palpitations were registered as side effects in isolated cases; these symptoms disappeared following a reduction in the dose of rescue salbutamol to $0 \cdot 2 \mathrm{mg}$. Hospital admission occurred in four cases, one patient during both treatment periods, one when on salmeterol, and one when receiving placebo. They were all given oral steroids for the acute exacerbation of their obstructive lung disease.

\section{Discussion}

The data presented from this double blind corssover study show that salmeterol $(50 \mu \mathrm{g}$ twice daily) produced significantly greater improvements than placebo in PEF, including a reduction in the diurnal variation in PEF, in smokers with moderate to severe chronic obstructive pulmonary disease. Furthermore, the requirement for bronchodilator treatment to relieve symptoms during the day and night were reduced. The treatment was well tolerated with a low incidence of pharmacologically predictable side effects and adverse effects.

In most studies in which the effect of bronchodilators has been studied in patients with COPD the emphasis has been on the effect of the drug on spirometric values. ${ }^{9}$ This might not be the most appropriate measurement as the present study has shown, in keeping with findings in previous studies, ${ }^{1011}$ no significant increases in $\mathrm{FEV}_{1}$ or FVC following regular treatment with salmeterol compared with placebo but significant differences in the subjective effect of active treatment and peak expiratory flow rates. These findings suggest that the therapeutic efficacy of bronchodilators in patients with COPD should probably be as- sessed from daily peak flow readings, adequacy of control of symptoms, and need for additional bronchodilator treatment.

The fact that acute challenges with $\beta$ agonists in the respiratory function laboratory often fail to show the considerable responsiveness considered characteristic of asthma has caused many to question the rationale for bronchodilator therapy in COPD. However, the findings in the present study suggest that this view may be unnecessarily pessimistic. As all the patients included in this study fulfilled the generally accepted criteria for a diagnosis of non-asthmatic obstructive pulmonary disease, the demonstrated effect of treatment with salmeterol cannot be ascribed to an admixture of patients with asthma. It may be argued that the magnitude of treatment effect - for example, the increase in morning peak expiratory flow rates - was small. The goal of $\beta$ agonist therapy is necessarily more modest in COPD than in asthma. ${ }^{12} \mathrm{~A}$ minor improvement in airflow in patients with COPD with moderate to severe obstruction may be of significant clinical benefit, especially if it reduces air trapping and by that the effort of breathing. ${ }^{9}$

Evidence from recent studies suggests that, as a group, the benefit from the addition of, for example, theophylline to an inhaled $\beta$ agonist in patients with COPD may be dependent on the chosen dose of $\beta$ agonist. ${ }^{1314}$ Obtained doseresponse relationships of inhaled $\beta$ agonists suggest that $200 \mu \mathrm{g}$ of salbutamol may not produce a response that reaches the plateau of the dose-response curve in patients with airways obstruction. ${ }^{1516}$ However, in the present study a dose of $400 \mu \mathrm{g}$ of salbutamol was given for acute relief of respiratory symptoms. It therefore seems unlikely that the beneficial effect of adding salmeterol to the treatment with salbutamol was caused by a suboptimal dose of salbutamol.

Baseline $\mathrm{FEV}_{1}$ and FVC were almost unchanged at the end of the salmeterol period and were certainly not significantly different from the placebo period. The degree of reversibility in $\mathrm{FEV}_{1}$ was, as expected, small in magnitude and, furthermore, unaffected by the treatment regimen. However, there is recent evidence that in COPD the acute response to an inhaled bronchodilator in the laboratory is of limited value in predicting the patient's long term response to either inhaled bronchodilators and/or theophylline. ${ }^{1617}$ Furthermore, there is only a modest correlation between level of $\mathrm{FEV}_{1}$ and severity of dyspnoea or exercise limitation ${ }^{1819}$ which probably indicates that the degree of airways obstruction is only partly responsible for the sensation of dyspnoea in patients with COPD. ${ }^{20}$ Although no improvement in spirometric values following treatment with salmeterol was observed, it seems reasonable to assume from the clinical response and improvement in PEF recordings that patients with moderate to severe COPD will benefit from long term treatment with long acting $\beta$ agonists.

This study was supported by Glaxo Denmark AS, DK-2605 Brøndby. 
1 American Thoracic Society. Standards for the diagnosis and (COPD) and asthma. Am Rev RespirDis 1986;136:225-44.

2 Ramsdell J, Nachtwey FJ, Moser KM. Bronchial hyperreactivity in chronic obstructive bronchitis. Am Rev Respir Dis 1982;126:829-32.

3 Ullman A, Svedmyr N. Salmeterol, a new long-acting inhaled $\beta_{2}$-agonist: comparison with salbutamol in adult haled $\beta_{2}$-agonist: comparison with salbut

4 Derom E, Pauwels R, Straeten van der M. Duration of the protective effect of salmeterol on methacholine challenge in asthmatics. Am Rev Respir Dis 1990;141 (part 2):A469.

5 Quanjer H, ed. Standardized lung function testing. Bull Eur Physiopathol Respir 1983;19(suppl):7-10

6 Lundback B, Rawlinson DW, Palmer JBD. Twelve month comparison of salmeterol and salbutamol as dry powder formulations in asthmatic patients. Thorax 1993;48:148-53.

7 Palmer JBD, Stuart HM, Shepherd GL, Viskum K. Inhaled salmeterol in the treatment of patients with moderate to salmeterol in the treatment of patients with moderate to
severe reversible obstructive airway disease - a 3 month severe reversible obstructive airway disease - a 3 month
comparison of the efficacy and safety of twice daily salcomparison of the efficacy and safety of twice daily salmeterol $(100$

86:409-17.
Pocock SJ. Clinical trials: a practical approach. London: John Pocock SJ. Clinical trials:
Wiley, 1984:110-22.

9 Canadian Thoracic Society Workshop Group. Guidelines for the assessment and management of chronic obstructive pulmonary disease. Can Med Assoc f 1992;147:420-8.

10 Teale C, Morrison JFJ, Jones PC, Muers MF. Reversibility tests in chronic obstructive airways disease: their predictive tests in chronic obstructive airways disease: their predictive
value with reference to benefit from domiciliary nebuliser value with reference to benefit from
therapy. Respir Med 1991;85:281-4

11 Evald T, Keittelmann S, Sindrup JH, Lange P. The effect of inhaled terbutaline on $\mathrm{FEV}_{1}, \mathrm{FVC}$, dyspnoea and walking distance in patients with chronic obstructive lung disease. Respir Med 1992;86:93-6.

12 Anthonisen N, Wright E. Response to inhaled bronchodilators in COPD. Chest 1987;91 (suppl 5):36S-9S.

13 Gyatt GH, Townsend M, Pugsley SO, Keller JL, Short HD, Taylor DW, et al. Bronchodilators in chronic airflow limitation. Effects on airway function, exercise capacity, limitation. Effects on airway function, exercise capacity,
and quality of life. Am Rev Respir Dis 1987;135:1069-74.

14 Tandon MK, Kailis SG. Bronchodilator treatment for partially reversible chronic obstructive airways disease. Thorax $1991 ; 46: 248-51$

15 Barnes PJ, Pride NB. Dose-response curves to inhaled $\beta$ adrenoceptor agonists in normal and asthmatic subjects. Br f Clin Pharmacol 1983;15:677-82.

16 Corris PA, Neville E, Nariman S, Gibson GJ. Dose-response study of inhaled salbutamol powder in chronic airflow study of inhaled salbutamol powd. Thorax 1983;38:292-6.

17 Taylor DR, Buich B, Kinney C. The efficacy of orally administered theophylline, inhaled salbutamol, and a comadministered theophylline, inhaled salbutamol, and a com-
bination of the two as chronic therapy in the management bination of the two as chronic therapy in the management
of chronic bronchitis with reversible air-flow obstruction. of chronic bronchitis with reversible

18 Mahler DA, Rosiello RA, Harver A. Comparison of clinical dyspnea ratings and psychosocial measurements of respiratory sensation in obstructive airways disease. $A m R e v$ Respir Dis 1987;135:1229-33.

19 Pineda H, Haas F. Accuracy of pulmonary function tests in predicting exercise tolerance in chronic obstructive pulmonary disease. Chest 1984;86:564-7.

20 Gottfried SB, Redline S, Altose MD. Respiratory sensation in chronic obstructive pulmonary disease. Am Rev Respir Dis 1985;132:954-9. 